ORIGINAL ARTICLE

\title{
Diagnosis of genital herpes by real time PCR in routine clinical practice
}

\author{
M Ramaswamy, C McDonald, M Smith, D Thomas, S Maxwell, M Tenant-Flowers, A M Geretti
}

Sex Transm Infect 2004;80:406-410. doi: 10.1136/sti.2003.008201

See end of article for authors' affiliations

Correspondence to A M Geretti, Royal Free and University College Medical School, Department of Virology, Hampstead Site, Rowland Hill Street, London NW3 2PF, UK; a.geretti@rfc.ucl. ac.uk

Accepted for publication 25 February 2004
Background: Virus isolation in cell culture is the recognised diagnostic gold standard for genital herpes. Although increasing evidence indicates that polymerase chain reaction (PCR) provides a more rapid and sensitive diagnostic method, its implementation in routine diagnostic settings has been limited by concerns over contamination and cost.

Objective: To evaluate the feasibility of replacing virus culture with PCR for the diagnosis of genital herpes in settings serving large populations of genitourinary medicine (GUM) attendees.

Methods: Genital swabs collected from 233 consecutive GUM attendees with suspected genital herpes were tested in parallel by virus culture and automated real time PCR. Three specimen preparation methods were evaluated and the assay reliability was assessed by repeat testing, comparison with a commercially available assay, and herpes simplex virus (HSV) sequence analysis. Probe melting temperatures (Tm) were used to differentiate between HSV types without additional post-PCR steps.

Results: HSV was detected in 79/233 (34\%) samples by virus culture and 132/233 (57\%) samples by PCR. PCR significantly increased HSV detection in both early $(<5$ days) and late ( $\geqslant 5$ days) presentations and in both first and recurrent episodes. HSV detection and typing by PCR was achieved within less than 4 hours leading to a significant reduction in labour compared to virus culture. Most specimens (120/132, 91\%) were typed as HSV-2. Results were highly reproducible.

Conclusions: Real time PCR is a highly reproducible, rapid, and labour efficient method for HSV detection in genital swabs. Its implementation is feasible in routine diagnostic settings.

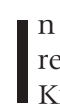
2002, over 18000 new cases of genital herpes were reported from genitourinary medicine clinics in the United Kingdom, making genital herpes the fourth most common sexually transmitted disease. ${ }^{1}$ These figures underestimate the true prevalence of symptomatic infections as atypical presentations are common and often misdiagnosed. ${ }^{2}$ Underdiagnosis of genital herpes is an important obstacle to effective management and control of transmission. The clinical diagnosis of genital herpes is both insensitive and non-specific and requires laboratory confirmation. ${ }^{3}{ }^{4}$ Virus isolation in cell culture has long been regarded as the diagnostic gold standard ${ }^{5}$ and is the diagnostic method of choice in the United Kingdom. ${ }^{6}$ Virus isolation is slow and labour intensive, requiring up to 7-10 days for the appearance of cytopathic changes in cultured cells or before a negative result can be issued. Specificity is virtually $100 \%$, but levels of virus shedding, quality of specimen, and transport conditions influence sensitivity. ${ }^{7-9}$ The rate of virus recovery declines significantly with time since the onset of lesions, from $52-93 \%$ for vesicles to $41-72 \%$ for ulcers and $19-27 \%$ for crusted lesions. ${ }^{8}{ }^{9}$ Furthermore, lack of specimen refrigeration after collection and during transport markedly reduces virus viability. ${ }^{7}$

Recent studies have shown that polymerase chain reaction (PCR) increases the rate of HSV detection in mucocutaneous swabs by $11-41 \%$ compared to virus culture. ${ }^{10}$ Although earlier PCR techniques were laborious, expensive and prone to contamination, newly developed real time PCR assays are fully automated and allow virus specific detection within a closed system, with fast turn around times and low risk of

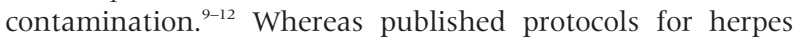
simplex virus (HSV) PCR do not always differentiate between HSV types, ${ }^{10}$ new technologies allow simultaneous detection and typing of HSV in a single reaction tube, based on software that analyses the different Tm values of HSV-1 and HSV-2 specific probes. ${ }^{11}{ }^{12}$ This is a valuable feature for the use of PCR in routine clinical practice, as differentiating between HSV types provides important prognostic information in genital herpes. ${ }^{13-16}$

The aim of this study was to compare the performance of virus culture and real time PCR for the diagnosis and typing of genital herpes in a clinical setting serving a large population of genitourinary medicine (GUM) clinic attendees. Three different specimen preparation methods were evaluated for their performance, cost, and labour intensity. Sequence variations within the target DNA polymerase gene region were investigated to assess their potential impact on the assay's performance.

\section{MATERIALS AND METHODS}

\section{Patient populations}

With ethics committee approval, genital swabs were collected from 233 consecutive GUM clinic attendees who presented with clinical features suggestive of genital herpes at the Caldecot Centre for Sexual Health at Kings College Hospital, London, between June 2002 and August 2002. The first part of the study recruited 145 consecutive patients. Their demographic and clinical data were recorded, including swab site, type of presentation (first or recurrent episode), duration of onset $(<5$ days or $\geqslant 5$ days $)$, presence of ulceration, administration of antiviral drugs before disease onset (aciclovir, valaciclovir, or famciclovir), and HIV status. In the second part of the study, 88 additional genital swabs from consecutive patients presenting with symptoms consistent with genital herpes in the same clinical setting were tested, to provide a validation group for the larger subset.

Abbreviations: BSA, bovine serum albumin; $\mathrm{CPE}$, cytopathic effect; FCS, fetal calf serum; GUM, genitourinary medicine; HSV, herpes simplex virus; $M E M$, minimal essential medium; $P C R$, polymerase chain reaction; PEG, polyethylene glycol; Tm, melting temperatures; VTM, viral transport medium 


\section{Sampling}

One swab was taken from each patient and placed in $2.5 \mathrm{ml}$ viral transport medium (VTM) containing minimal essential medium (MEM) balanced with 25 mM Hepes (BioWhittaker, Europe) supplemented with $10 \%$ bovine serum albumin (BSA), $7.5 \%$ sodium bicarbonate, penicillin $(500 \mathrm{U} / \mathrm{ml})$, streptomycin $(1 \mathrm{mg} / \mathrm{ml})$ and amphotericin B $(5 \mu \mathrm{g} / \mathrm{ml})$. In the laboratory, samples were vortexed for 30 seconds and separated into five aliquots of $500 \mu \mathrm{l}$ to be used for parallel virus culture and PCR.

\section{Virus culture and typing}

For virus isolation, $200 \mu \mathrm{l}$ of the specimen in VTM were inoculated into two tubes containing a monolayer of Vero monkey kidney cells. Cultures were maintained in MEMHepes growth medium (BioWhittaker) supplemented with $25 \%$ fetal calf serum (FCS), and incubated at $37^{\circ} \mathrm{C}$ for 10 days. Cell cultures were examined daily for the appearance of a cytopathic effect (CPE). When a CPE was observed, the cells were scraped off the tube, dried on a slide, fixed in acetone and stained with fluorescein labelled murine monoclonal antibodies against HSV-1 and HSV-2 (Syva Microtak, Palo Alto, CA, USA) according to manufacturer's instructions.

\section{Specimen preparation for PCR}

With a subset of 140 samples, three different methods were used to prepare DNA from $200 \mu \mathrm{l}$ of specimen in VTM: (1) manual DNA extraction with the QIAamp DNA Mini Kit (Qiagen, UK); (2) automated DNA extraction with the MagNA Pure LC (Roche Diagnostics, Germany), and (3) DNA precipitation with polyethylene glycol (PEG) and sodium chloride $(\mathrm{NaCl})$. The QIAamp DNA Mini Kit was used in accordance with manufacturer's instructions with the following modifications: an aqueous solution of poly $\mathrm{dA}$ (5 $\mu \mathrm{g} / \mathrm{ml}$ ) (Amersham Biosciences, UK) was added during lysis and $230 \mu \mathrm{l}$ of $99 \%$ ethanol was used at the first wash step to improve extraction in all samples. For the MagNA Pure LC instrument, the sample material was placed into the wells of the sample cartridge, with binding/lysis buffer, proteinase $\mathrm{K}$ and extraction carried out according to the manufacturer's instructions. DNA was eluted in $60 \mu \mathrm{l}$ of sterile PCR grade deionised water (Sigma, UK) for the QIAamp DNA Mini kit and in $100 \mu \mathrm{l}$ of elution buffer (Total Nucleic Acid Isolation kit, Roche Diagnostics) for the MagNA Pure LC system. PEG precipitation was performed by adding $200 \mu \mathrm{l}$ of the specimen in VTM to a mixture of $2.5 \mathrm{M} \mathrm{NaCl}(25$ $\mu \mathrm{l})$ and $20 \%$ PEG $8000(25 \mu \mathrm{l})$. The mixture was vortexed, incubated on ice for 30 minutes, and centrifuged at $11000 \mathrm{~g}$ for 20 minutes at $4^{\circ} \mathrm{C}$. The supernatant was aspirated, pellet recentrifuged at $4^{\circ} \mathrm{C}$ for 5 minutes before the pellet was resuspended in $20 \mu \mathrm{l}$ of deionised water.

Real time PCR was performed with the LightCycler (Roche Diagnostics) using a method previously described, that amplifies a $215 \mathrm{bp}$ region of the viral DNA polymerase gene. ${ }^{11}{ }^{12}{ }^{17}$ A total volume of $20 \mu \mathrm{l}$ was obtained by adding $5 \mu \mathrm{l}$ of DNA or precipitated virus to a PCR reaction mix in glass capillaries. DNA amplification was achieved using the Roche LC Fast Start DNA Master Hybridisation Probe kit (Roche Diagnostics) as described by the manufacturer. Forward (HSV POL F 5'-GCTCGAGTGCGAAAAAACGTTC$3^{\prime}$ ) and reverse primers (HSV POL A 5'-TGCGGTTGATAAA CGCGCAGT-3') and two fluorescently labelled hybridisation probes HSV-2 FLU (5'-gCgCACCAgATCCACgCCCTTgATg AgC-FAM-3') and HSV-2 LCR (5'-LC Red 640-CTTgCCCCCgC AgATgACgCC phosphate-3') (TIB MolBiol, Germany) were used at $5 \mu \mathrm{M}$ and $1 \mu \mathrm{M}$ respectively.

PCR conditions were as follows: initial denaturation at $95^{\circ} \mathrm{C}$ for 10 minutes (temperature transition rate of $20^{\circ} \mathrm{C} / \mathrm{s}$ ) to activate DNA Taq polymerase, followed by 50 cycles of denaturation at $95^{\circ} \mathrm{C}$ for 5 seconds $\left(20^{\circ} \mathrm{C} / \mathrm{s}\right.$ transition), annealing at $50^{\circ} \mathrm{C}$ for 5 seconds $\left(20^{\circ} \mathrm{C} / \mathrm{s}\right.$ transition $)$ with single fluorescence acquisition, and extension at $72^{\circ} \mathrm{C}$ for 5 seconds $\left(20^{\circ} \mathrm{C} / \mathrm{s}\right.$ transition). Melting curve analysis was performed as follows: annealing at $40^{\circ} \mathrm{C}$ for 30 seconds $\left(20^{\circ} \mathrm{C} / \mathrm{s}\right.$ transition) followed by an increase to $80^{\circ} \mathrm{C}$ for 0 second $\left(0.1^{\circ} \mathrm{C} / \mathrm{s}\right.$ transition) with continuous fluorescence acquisition, and cooling to $40^{\circ} \mathrm{C}$ for 30 seconds $\left(20^{\circ} \mathrm{C} / \mathrm{s}\right.$ transition $)$. The Tm of DNA fragments and hybridisation probes was used to differentiate between HSV types. The probe Tm was $59^{\circ} \mathrm{C}$ for HSV-l and $64^{\circ} \mathrm{C}$ and/or $71{ }^{\circ} \mathrm{C}$ for HSV-2. The RealArt HSVI/2 LC PCR kit (Artus Biotech, Germany) was used according to the manufacturer's instructions to confirm the results of $15 \mathrm{HSV}$ positive specimens.

\section{DNA sequencing}

Samples were prepared for LightCycler PCR as described earlier but in the absence of hybridisation probes HSV-2 FLU and LCR. The final volume of $20 \mu \mathrm{l}$ was made up with deionised water. Following amplification, the DNA was purified using QIAquick PCR Purification kits (Qiagen) according to manufacturer's instructions and eluted in $50 \mu \mathrm{l}$ of deionised water.

DNA sequencing was performed by the Sanger dideoxy chain termination method using $3 \mu \mathrm{l}$ of extracted DNA, $1 \mu \mathrm{l}$ of each A, C, G, T reagent mix from the ThermoSequenase DYEnamic Direct Cycle sequencing kit (Amersham Pharmacia Biotech Inc, UK), $1 \mu \mathrm{l}$ of $0.5 \mu \mathrm{M}$ HSV forward and reverse primers (as previously described) labelled with CY5.5 and CY5 respectively (Sigma-Genosys Ltd, UK). Reactions were performed on a GeneAmp 9700 thermocycler (PerkinElmer Applied Biosystems, Beaconsfield, UK) under the following conditions: 25 cycles of denaturation at $94^{\circ} \mathrm{C}$ for 5 minutes, followed by further denaturation at $94^{\circ} \mathrm{C}$ for 30 seconds, annealing at $50^{\circ} \mathrm{C}$ for 30 seconds, and extension at $70^{\circ} \mathrm{C}$ for 1 minute. Formamide loading dye $(7 \mu \mathrm{l})$ was added, and the DNA denatured at $80^{\circ} \mathrm{C}$ for 2 minutes. Automated DNA sequencing reactions $(2 \mu \mathrm{l})$ were run on an Trugene HIV-l Opengene sequencing system (Visible Genetics, Ontario, Canada) under standard conditions using version 3.16 software as described by the manufacturer. Sequence data were compared to other HSV sequences present in the GenBank database to confirm HSV type using BLAST. ${ }^{18}$ Sequences were aligned using ClustalW version $1.81 .^{19}$

\section{Analysis of results}

The HSV detection rates for virus culture versus PCR according to clinical characteristics were compared by the $\chi^{2}$ or Fisher's exact test as appropriate. In the comparison of specimen preparation methods, the "true positive" reference was specimens that were either positive in both virus culture and PCR, or were virus culture negative but PCR positive in $\geqslant 2$ separate assays and by $\geqslant 2$ methods. Kappa values were calculated to determine the level of agreement of the three specimen preparation methods when compared to the reference.

\section{RESULTS}

In the first part of the study genital swabs were collected from 145 consecutive patients ( 85 men and 60 women) with suspected genital herpes, and tested in parallel by virus culture and PCR. The most common swab sites were the penile skin in males $(63 / 85,74 \%)$ and the vulva in females $(48 / 60,80 \%)$. HSV was detected in $45 / 145$ (31\%) specimens by culture and $77 / 145(53 \%)$ specimens by PCR. The 32 specimens that were negative by culture but positive by PCR underwent extensive retesting. They were all confirmed HSV 
Table 1 Comparison of virus culture (VC) and PCR for HSV detection in different clinical presentations of genital herpes

\begin{tabular}{llll}
\hline & & HSV positive \\
\cline { 2 - 4 } & & VC & PCR \\
& Total & No (\%) & No (\%) \\
\hline First episode & 83 & $26(31)$ & $41(49)$ \\
Recurrent episode & 62 & $19(31)$ & $36(58)$ \\
Onset $<5$ days & 64 & $27(42)$ & $38(59)$ \\
Onset $\geqslant 5$ days & 81 & $18(22)$ & $39(48)$ \\
Visible ulceration & 97 & $33(34)$ & $62(64)$ \\
No visible ulceration & 48 & $12(25)$ & $15(31)$ \\
HIV positive & 17 & $7(41)$ & $12(71)$ \\
HIV negative & 58 & $20(34)$ & $32(55)$ \\
HIV status unknown & 70 & $18(26)$ & $33(47)$ \\
Men & 85 & $24(28)$ & $43(51)$ \\
Women & 60 & $21(35)$ & $34(57)$ \\
Total & 145 & $45(31)$ & $77(53)$ \\
\hline
\end{tabular}

DNA positive in $\geqslant 2$ independent replicate PCR assays (mean 2.75 assays per sample). In addition, with a random subset of 15 samples, the in-house PCR results were confirmed by a commercially available PCR assay. Thus real time PCR increased the HSV detection rate by $71 \%$ (32/45). High reproducibility indicated a low risk of false positive results. No patient with positive culture had a negative PCR. The average time for a positive virus culture was 3 days (range 210 days), whereas negative results required 10 days of incubation. PCR results required less than 4 hours including time for specimen preparation, amplification, detection, analysis, and typing.

Table 1 shows the results of virus culture and PCR in relation to clinical presentation. By either method the rates of HSV detection were similar in men and women, and PCR increased HSV detection by $79 \%(19 / 24)$ and $62 \%$ (13/21) in the two groups respectively. Culture was more frequently positive in patients presenting $<5$ days of onset than in those who presented later $(27 / 64,42 \%$ versus $18 / 8122 \%$, p $=0.01)$. The proportion of patients with a positive PCR did not differ significantly between the two groups (38/64, 59\% versus 39/ $81,48 \%, p=0.2)$. As a result, PCR increased HSV detection by $41 \%(11 / 27)$ in early disease and $116 \%(21 / 18)$ in late disease. The proportion of patients with a positive culture was similar in first episode and recurrent disease. PCR increased HSV detection by $58 \%(15 / 26)$ and $89 \%(17 / 19)$ in the two groups respectively. Improved detection by PCR was seen regardless of HIV status.
We subsequently extended the study to compare virus culture with PCR in further 88 consecutive genital swabs obtained from symptomatic patients in the same clinical setting. Of these, $34 / 88$ (39\%) were positive by culture and $55 / 88(63 \%)$ by PCR. Thus, in this additional subset of samples, PCR increased HSV detection by 62\% (21/34), validating the data from the larger subset. In the whole cohort, HSV detection rate was 79/233 (34\%) by virus culture and 132/233 (57\%) by PCR.

\section{HSV typing by LightCycler PCR}

Figure 1 shows the reference Tm for HSV-1 and HSV-2. Among the first set of HSV positive samples, 71/77 (92\%) were typed as HSV-2 and 6/77 (8\%) as HSV-1. All typing results were confirmed in the replicate experiments. The 15 samples tested by the commercial PCR assay also yielded typing results identical to those obtained by the in-house assay. Among the second set of HSV positive samples, 49/55 (89\%) were typed as HSV-2 and 6/55 (11\%) as HSV-1. In the whole cohort, 120/132 (91\%) HSV positive samples were typed as HSV-2. Fourteen randomly selected HSV-2 positive samples with $\mathrm{Tm}>60^{\circ} \mathrm{C}$ were sequenced and all confirmed as HSV-2 after alignment to known HSV-2 sequences (table 2). Among the 14 samples sequenced, four showed sequence variation in the FLU probe binding site within the $100 \mathrm{bp}$ region of the DNA polymerase gene (table 2). No variation was observed in the target HSV-2 sequence among the 10 remaining specimens.

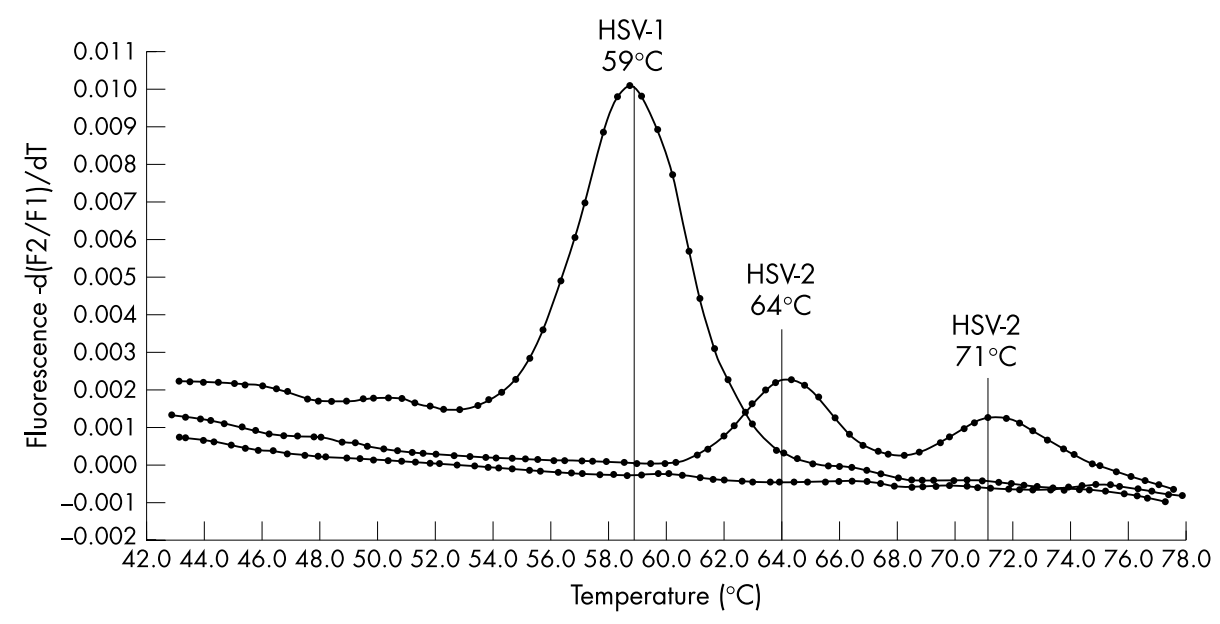

Figure 1 LightCycler melting curve analysis for HSV typing. 
Table 2 Nucleotide sequences of HSV positive specimens with $\mathrm{Tm}>60^{\circ} \mathrm{C}$. Probes are boxed and nucleotide differences are bold

\begin{tabular}{lc}
\hline Specimen & HSV-2 sequence \\
\hline $\begin{array}{l}\text { HSV-2 Control } \\
\text { Probe LCR }\end{array}$ & GGCGTCATCTGCGGGGGCAAGATGCTCATCAAGGGCGTG-GATCTG-GTGCGCAAAAAC \\
Probe FLU & GCTCATCAAGGGCGTG-GATCTG-GTGCGC \\
1 & CGGCGTCATCTGCGGGGGCAAGATGCTCATTAAGGGCGTC-GACCTG-GTGCGCAAAAAC \\
2 & CGGCGTCATCTGCGGGGGCAAGATGCTCATCAAGGGCGTG-GATCTG-GTGCGCAAAAAC \\
3 & CGGCGTCATCTGCGGGGGCAAGATGCTCATCAAGGGCGTG-GATCTG-GTGCGCAAAAAC \\
4 & CGGCGTCATCTGCGGGGGCAAGATGCTCATCAAGGGCGTG-GATCTG-GTGCGCAAAAAC \\
5 & CGGCGTCATCTGCGGGGGCAAGATGCTCATCAAGGGCGTG-GATCTG-GTGCGCAAAAAC \\
6 & CGGCGTCATCTGCGGGGGCAAGATGCTCATCAAGGGCGTG-GATCTG-GTGCGCAAAAAC \\
7 & CGGCGTCATCTGCGGGGGCAAGATGCTCATCAAGGGCGTG-GATCTG-GTGCGCAAAAAC \\
8 & CGGCGTCATCTGCGGGGGCAAGATGCTCATCAAGGGCGTG-GATCTG-GTGCGCAAAAAC \\
9 & CGGCGTCATCTGCGGGGGCAAGATGCTCATCAAGGGCGTG-GATCTG-GTGCGCAAAAAC \\
10 & CGGCGTCATCTGCGGGGGCAAGATGCTCATTAAGGGCGTC-GACCTG-GTGCGCAAAAAC \\
11 & CGGCGTCATCTGCGGGGGCAAGATGCTCATCAAGGGCGTG-GATCTG-GTGCGCAAAAAC \\
12 & CGGCGTCATCTGCGGGGGCAAGATGCTCATCAAGGGCGTG-GATCTG-GTGCGCAAAAAC \\
13 & CGGCGTCATCTGCGGGGGCAAGATGCTCATCAAGGGCGTGAGATCTG-GTGCGCAAA--- \\
14 & CGGCGTCATCTGCGGGGGCAAGATGCTCATCAAGGGCGTG-GATCTGTGTGCGCAAAAC \\
\hline
\end{tabular}

Feasibility of PCR testing for large volumes of samples As specimen preparation is the most time consuming step in PCR testing, we compared the performance, labour intensity, and cost of three specimen preparation methods using manual DNA extraction with the QIAamp DNA mini kit, automated DNA extraction with MagNA Pure LC, and virus precipitation with PEG. In a comparison of 140 specimens, $120 / 140(86 \%)$ were either negative or positive by all three methods, 12/140 (8\%) were positive by two methods, and $8 / 140(6 \%)$ were positive by only one method. Of the latter eight samples, all were confirmed positive by repeated specimen preparation and PCR testing, three were also positive by virus culture. Regarding as "true positive" specimens that were either positive by both virus culture and PCR or, if virus culture negative, positive in $\geqslant 2$ separate PCR assays and by $\geqslant 2$ methods, the HSV detection rate was PEG precipitation $>$ MagNA Pure LC $>$ QIAamp DNA mini kit (table 3). Kappa values for the three specimen preparation methods were $\geqslant 0.84$, indicating a high level of agreement. PEG precipitation detected 65/72 (90\%) positive samples, including three samples positive by virus culture but negative by the other two preparation methods, and was more rapid and less expensive than the other two methods (table 3 ).

\section{DISCUSSION}

A virological confirmation of genital herpes provides the basis for appropriate management, and informs prognosis and counselling. To date, the routine diagnosis of genital herpes has mainly relied on virus isolation in cell culture. However, numerous recent reports have highlighted the limitations of this method. ${ }^{9}$ On practical consideration, virus culture is time consuming and requires highly stringent conditions for specimen transport and storage to preserve virus viability. ${ }^{7}$ Improved diagnostic methods are needed to improve recognition of genital herpes. In this study we demonstrated that real time PCR significantly increased the rate of HSV detection in genital swabs compared to virus culture and that its implementation is feasible for routine diagnostic settings.

PCR was shown to increase the overall rate of HSV detection by $61-71 \%$. Even in patients presenting with visible genital ulcerations PCR detected $88 \%$ more infections than virus culture. Thus, in the absence of PCR testing, 53 of the 233 symptomatic patients would have received a negative result, preventing appropriate counselling on prognosis and risk of transmission. Our result is striking considering that a similar study by Scoular ${ }^{9}$ showed a $24 \%$ increased detection rate by PCR over virus culture. This observation may in part be because our study was conducted during summer months. Warm weather may have affected HSV viability after specimen collection and further diminished the sensitivity of virus culture. $^{7}$

The increase in detection afforded by PCR was observed in different clinical presentations including both first and recurrent episodes. In contrast with previous observations, ${ }^{20}$ we did not observe a different yield of virus culture in patients with first episode compared with those with recurrent disease. Predictably, the increase in detection by

Table 3 Comparison of detection rate, duration and cost of three PCR testing methods and virus culture

\begin{tabular}{lllll}
\hline & \multicolumn{2}{l}{ DNA extraction } & & \\
\cline { 2 - 3 } & Manual & Automated & Virus precipitation & Virus culture \\
\hline Relative detection rate* & $61 / 72(85 \%)$ & $62 / 72(86 \%)$ & $65 / 72(90 \%)$ & $42 / 72(58 \%)$ \\
Duration (minutes or days): & & & & \\
Specimen preparation & 90 & 120 & 60 & - \\
PCR & 81 & 101 & 81 & - \\
$\quad$ Total & 171 & 221 & 141 & $2-10$ days \\
Reagent cost per test (£): & 3.99 & 9.27 & 2.44 & Negative sample: 1.00 \\
& & & & Positive samplet: 1.55 \\
\hline
\end{tabular}

*True positive: specimens that had tested HSV positive in both virus culture and PCR, or if virus culture negative, positive in $\geqslant 2$ separate PCR assay and by $\geqslant 2$ methods. †Typed by direct immunofluorescence. 
PCR was especially high among patients presenting late $(\geqslant 5$ days) after the onset of symptoms, as declining levels of virus shedding in older lesions would favour the more sensitive technique. ${ }^{90}$ None the less, detection also increased significantly in patients who presented within 5 days of onset. The absence of a significant difference between culture and PCR yields in patients without visible ulceration is interesting, but the small number of observations precludes speculations about its significance.

Unlike a previous study by Scoular et $a l^{10}$ the PCR method we used offered the advantage of providing HSV typing without additional, time consuming post-PCR steps. Sequencing of a subset of HSV-2 positive samples confirmed the accuracy of typing. The low level of sequence variation observed indicated high reliability of the assay. Among 132 HSV positive specimens, $91 \%$ were HSV-2 and $9 \%$ were HSV-1. HSV-2 accounted for the majority of both first and recurrent episodes. These findings are in contrast with results from other centres in the United Kingdom, which report HSV-1 to be responsible for more than $\geqslant 50 \%$ of newly diagnosed cases of genital herpes..$^{21-23}$

To investigate the feasibility of implementing HSV PCR for large volume testing, three specimen preparation methods were compared to evaluate performance, labour, and cost. A high level of agreement was observed between the three methods. Virus precipitation by PEG, although not previously used for LightCycler PCR, had the highest detection rates, was the least expensive, and required the shortest incubation period, thus providing a valid option for specimen processing before PCR. Even though PCR has demonstrated increased sensitivity over virus culture, its implementation into routine clinical practice has been limited by concerns of contamination. Extensive retesting of positive samples in our study demonstrated that real time PCR assays are reliable and highly reproducible. This is a result of amplification occurring within a closed system, with a minimal risk of carryover contamination, although reproducibility was also helped by the high prevalence of disease in our sample. ${ }^{24}$ Although the costs of consumables for PCR (£2.44-£9.27) are higher than those for virus culture $(£ 1.00-£ 1.55)$, real time PCR proved cost efficient by significantly reducing labour cost per sample.

With high levels of asymptomatic shedding and high prevalence of non-classic presentations, laboratory investigations provide guidance for patient management and controlling the spread of HSV infection. The sensitivity of nucleic acid amplification tests exceeds conventional laboratory methods to detect HSV, thus enabling greater diagnostic accuracy. Although virus culture continues to be the standard diagnostic test used in routine practice in the United Kingdom (D Brown and AM Geretti, unpublished observation), its ability to detect HSV in a large proportion of infected individuals is clearly deficient compared to PCR. Our data strongly support the implementation of PCR for the routine diagnosis of genital herpes.

\section{Key messages}

- Real time PCR is a highly reproducible, rapid, and labour efficient method for HSV detection in genital swabs

- The ability of virus culture to detect HSV in a large proportion of infected individuals is clearly deficient compared to PCR

- The implementation of real time PCR for the detection of HSV in genital swabs is feasible for routine diagnostic settings

\section{ACKNOWLEDGEMENTS}

The authors thank Dr Benedict Murdin (University of Surrey in Guildford, UK), for statistical support.

\section{CONTRIBUTORS}

Study design: AMG, MS, MT-F; experimental work: MR, DT, SMl, MS; coordination of sampling and clinical data collection: $\mathrm{CMCD}$; analysis of results: $M R, A M G, M S$; preparation of manuscript: $M R$, AMG.

\section{Authors' affiliations}

M Ramaswamy, A M Geretti, Royal Free and University College Medical School, Department of Virology, Hampstead Site, Rowland Hill Street, London NW3 2PF, UK

C McDonald, M Tenant-Flowers, Department of Genitourinary and HIV Medicine, Caldecot Centre, King's College Hospital, London SE5 9RS, UK

M Smith, D Thomas, S Maxwell, Department of Infection and Health Protection Agency, Guy's King's and St Thomas's School of Medicine, Kings College Hospital, East Dulwich Grove, London SE22 8QF, UK

Conflict of interest: None declared.

\section{REFERENCES}

1 www.hpa.org.uk/infections/topics_az/hiv_and_sti/sti-herpes/ epidemiology/epidemiology.htm (last accessed in December 2003).

2 Corey L. The current trend in genital herpes. Progress in prevention. Sex Transm Dis 1994;21:S38-44.

3 Mullan HM, Munday PE. The acceptability of the introduction of a type specific herpes antibody screening test into a genitourinary medicine clinic in the United Kingdom. Sex Transm Infect 2003;79:129-33.

4 Cowan FM, Johnson AM, Ashley R, et al. Antibody to herpes simplex virus type 2 as serological marker of sexual lifestyle in populations. BMJ 1994:309:1325-9.

5 Ashley RL. Laboratory techniques in the diagnosis of herpes simplex infection. Genitourin Med 1993;69:174-83.

6 Scoular A, Kinghorn G. British Co-operative Clinical Group national survey on diagnostic issues surrounding genital herpes. MSSVD Special Interest Group on Genital Herpes and the British Co-operative Clinical Group. Sex Transm Infect 1999:75:403-5

7 Wald A, Huang ML, Carrell D, et al. Polymerase chain reaction for detection of herpes simplex virus (HSV) DNA on mucosal surfaces: comparison with HSV isolation in cell culture. J Infect Dis 2003;188:1345-51.

8 Corey L, Adams HG, Brown ZA, et al. Genital herpes simplex virus infections: clinical manifestations, course, and complications. Ann Intern Med 1983;98:958-72.

9 Scoular A. Using the evidence base on genital herpes: optimising the use of diagnostic tests and information provision. Sex Transm Infect 2002;78:160-5.

10 Scoular A, Gillespie G, Carman WF. Polymerase chain reaction for diagnosis of genital herpes in a genitourinary medicine clinic. Sex Transm Infect 2002;78:21-5

11 Espy MJ, Rys PN, Wold AD, et al. Detection of herpes simplex virus DNA in genital and dermal specimens by LightCycler PCR after extraction using the IsoQuick, MagNA Pure, and BioRobot 9604 methods. J Clin Microbio 2001;39:2233-6.

12 Burrows J, Nitsche A, Bayly B, et al. Detection and subtyping of herpes simplex virus in clinical samples by LightCycler PCR, enzyme immunoassay, and cell culture. BMC Microbiol 2002;2:2-12.

13 Benedetti J, Corey L, Ashley R. Recurrence rates in genital herpes after symptomatic first-episode infection. Ann Intern Med 1994;121:847-54.

14 Lafferty WE, Coombs RW, Benedetti J, et al. Recurrences after oral and genital herpes simplex virus infection. Influence of site of infection and viral type. N Engl J Med 1987;316:1444-9.

15 Benedetti JK, Zeh J, Corey L. Clinical reactivation of genital herpes simplex virus infection decreases in frequency over time. Ann Intern Med 1999;131:14-20.

16 Koelle DM, Wald A. Herpes simplex virus: the importance of asymptomatic shedding. J Antimicrob Chemother 2000;45(Suppl T3):1-8.

17 Espy MJ, Uhl JR, Mitchell PS, et al. Diagnosis of herpes simplex virus infections in the clinical laboratory by LightCycler PCR. J Clin Microbiol 2000;38:795-9. 18 www.ncbi.nlm.nih.gov/BLAST.

19 clustalw. genome.ad. ip.

20 Corey L, Holmes KK. Genital herpes simplex virus infections: current concepts in diagnosis, therapy, and prevention. Ann Intern Med 1983;98:973-83.

21 Narouz N, Allan PS, Wade AH. Genital herpes: general practitioners' knowledge and opinions. Sex Transm Infect 2002;78:198-200.

22 Scoular A, Norrie J, Gillespie G, et al. Longitudinal study of genital infection by herpes simplex virus type 1 in western Scotland over 15 years. BMJ 2002;324:1366-7.

23 Coyle PV, O'Neill HJ, Wyatt DE, et al. Emergence of herpes simplex type 1 as the main cause of recurrent genital ulcerative disease in women in Northern Ireland. J Clin Virol 2003;27:22-9.

24 Van Doornum GJ, Guldemeester J, Osterhaus AD, et al. Diagnosing herpesvirus infections by real-time amplification and rapid culture. J Clin Microbiol 2003;41:576-80. 